\title{
Role and regulation of EGFR in actin remodeling in sperm capacitation and the acrosome reaction
}

\author{
Haim Breitbart and Nir Etkovitz
}

To bind and fertilize the egg, the spermatozoon should undergo few biochemical and motility changes in the female reproductive tract collectively called capacitation. The capacitated spermatozoon binds to the egg zona pellucida, and then undergoes the acrosome reaction (AR), which allows its penetration into the egg. The mechanisms regulating sperm capacitation and the AR are not completely understood. In the present review, we summarize some data regarding the role and regulation of the epidermal growth factor receptor (EGFR) in these processes. In the capacitation process, the EGFR is partially activated by protein kinase A (PKA), resulting in phospholipase D (PLD) activation and actin polymerization. Protein kinase $\mathrm{C}$ alpha (PKC $\alpha$ ), which is already activated at the beginning of the capacitation, also participates in PLD activation. Further activation of the EGFR at the end of the capacitation enhances intracellular $\mathrm{Ca}^{2+}$ concentration leading to F-actin breakdown and allows the AR to take place. Under in vivo conditions, the EGFR can be directly activated by its known ligand epidermal growth factor (EGF), and indirectly by activating PKA or by transactivation mediated by G protein-coupled receptors (GPCRs) activation or by ouabain. Under physiological conditions, sperm PKA is activated mainly by bicarbonate, which activates the soluble adenylyl cyclase to produce cyclic adenosine monophosphate (cAMP), the activator of PKA. The GPCR activators angiotensin II or lysophosphatidic acid, as well as ouabain and EGF are physiological components present in the female reproductive tract.

Asian Journal of Andrology (2011) 13, 106-110; doi:10.1038/aja.2010.78; published online 18 October 2010

Keywords: acrosome reaction; capacitation; PI3K; PKA; PKC; spermatozoa

\section{INTRODUCTION}

Ejaculated mammalian spermatozoa should reside in the female genital tract for several hours before gaining the ability to fertilize the egg. In human sperm, however, sperm must move out of the seminal plasma immediately after ejaculation and appear in the fallopian tube within minutes. As soon as sperm are moving out of the ejaculate and passing the cervical mucus, they undergo several biochemical changes collectively called capacitation (reviewed in Florman and Ducibella ${ }^{1}$ and Gadella and Visconti ${ }^{2}$ ). These changes are still not clear, but it seems certain to involve molecules absorbed on, or integrated into, the sperm plasma membrane during epididymal maturation, and on contact of spermatozoa with the seminal plasma they render the spermatozoa capable of fertilization. The removal or alteration of these molecules prepares the sperm toward successful binding to the egg and fertilization. It was shown by Yanagimachi and $\mathrm{Chang}^{3}$ that capacitation can be mimicked in vitro, making the analysis of capacitation mechanisms considerably easier.

During mammalian fertilization, the capacitated spermatozoon penetrates the cumulus oophrous of the ovum, and then binds to the zona pellucida with its plasma membrane intact. After binding to the egg zona pellucida, the spermatozoon undergoes an exocytotic process called the acrosome reaction (AR) (reviewed in Yanagimachi et al., ${ }^{4}$ Roldan and Shi, ${ }^{5}$ Florman et al. ${ }^{6}$ and Breitbart ${ }^{7}$ ). This event is required for fertilization, because it enables passage of the spermatozoon through the zona pellucida and its subsequent fusion with the egg oolema. Therefore, elucidation of the mechanisms regulating the $\mathrm{AR}$ is important for understanding the process of mammalian fert- ilization. In our laboratory and others it was shown that variety of agonists can trigger the AR via receptor-mediated mechanisms. ${ }^{1,6,8-10}$ Although zona pellucida-derived glycoproteins are thought to be the physiological inducers of the $\mathrm{AR},{ }^{11,12}$ the reaction can be induced in vitro by various constituents of the female reproductive tract including progesterone, ${ }^{13,14}$ prostaglandins, ${ }^{15}$ atrial natriuretic peptide, ${ }^{16}$ epidermal growth factor (EGF), ${ }^{9,10,17}$ ouabain $^{10}$ and other ligands. These agonists may have a direct and/or synergistic effect with other constituents of the female reproductive ${ }^{10}$ or on the zona pellucida. ${ }^{14}$ The question regarding the physiological role of these factors under in vivo conditions is still an open question. Assuming that acrosomereacted sperm cannot bind and fertilize the egg, we suggest that premature AR before reaching the egg zona pellucida, might be a way of selection in which the 'bad' sperm will undergo the so-called nonspecific AR and would not be able to fertilize, whereas the 'best' selected sperm will reach the egg in its intact morphology and will fertilize it. Thus, to study the selection mechanism, it is very important to understand the mechanism of action of the various physiological factors that induce the AR. One of these mechanisms, the EGF receptor (EGFR) system is described in this review.

\section{ACTIN REMODELING IN SPERM CAPACITATION AND BEFORE THE AR}

In recent years, our laboratory focused on the formation of actin filaments during mammalian sperm capacitation and the depolymerization of these filaments before the AR. ${ }^{18}$ The formation of F-actin 
during capacitation was observed mainly in the sperm head and also in the tail. ${ }^{18,19}$ It was shown almost 30 years ago that in echinoderm sperm, actin can be polymerized and that actin is localized in the microfilaments in the acrosomal process. ${ }^{20}$ Later, it was suggested that sperm motility is affected by the rapid polymerization of actin. ${ }^{21}$ In our early studies with isolated bovine sperm membranes, we suggested that F-actin network located between the plasma membrane and the outer acrosomal membrane forms a scaffold that immobilizes phospholipase C- $\gamma 1$, which is involved in the AR (reviewed in Breitbart and Spungin $^{22}$ ) The observation that both actin depolymerization ${ }^{23}$ and membrane fusion ${ }^{24}$ require relatively high calcium concentration (in the $\mathrm{mmol} \mathrm{l}^{-1}$ range) supports the notion that actin filaments constitute the final barrier to fusion (reviewed in Breitbart and Spungin ${ }^{22}$ ). We have recently suggested that translation of nuclear-encoded proteins occurs in sperm mitochondria during capacitation, ${ }^{25}$ and this finding was later confirmed by sperm proteomics approach. ${ }^{26}$ In other cell types, it was shown that mRNA can be translocated on actin filaments to the translation location in the cell; thus we suggested that the formation of $\mathrm{F}$-actin during sperm capacitation might be important for the translocation of nuclear mRNA to the sperm mid-piece where the mitochondria are located.

We previously demonstrated that the process of actin polymerization depends on phospholipase D (PLD) activity. ${ }^{27}$ We have shown that this activity is regulated by the crosstalk between the protein kinases $\mathrm{A}$ and $\mathrm{C}(\mathrm{PKA} / \mathrm{PKC}){ }^{27}$ In a more recent publication, we demonstrated that phosphatidylinositol 4-kinase (PI4K) regulate the activity of PLD by its activity product phosphatidylinositol 4,5bisphosphate $\left(\mathrm{PIP}_{2(4,5)}\right)$ that is required as a cofactor for the activation of PLD in many cell types. ${ }^{19,28-31}$ It was shown that $\mathrm{PIP}_{2}$ is produced gradually during sperm capacitation and, in parallel, PLD activity and F-actin levels are increased. We also show that spermine $\left(10 \mu \mathrm{moll}^{-1}\right)$, a constituents of the semen, can enhance the activity of PI4K, leading to increase in the production of $\mathrm{PIP}_{2(4,5)}$. This enhancement in PI4K and PLD activity is accompanied by elevation in actin polymerization. ${ }^{19,27}$ Furthermore $\operatorname{PIP}_{2(4,5)}$ serves as a precursor for two welldefined second messengers produced by its phospholipase $\mathrm{C}$-catalyzed hydrolysis; ${ }^{32}$ diacylglycerol, which activates PKC, ${ }^{33}$ and inositol 1,4,5triphosphate, which mobilizes $\mathrm{Ca}^{2+}$ from intracellular stores. ${ }^{32} \mathrm{PKC}$ is involved in sperm AR and actin polymerization ${ }^{19,27}$ and inositol 1,4,5triphosphate is involved in intracellular calcium regulation in sperm. ${ }^{34-36}$

It is not clear how PI4K is regulated in sperm capacitation. We show elsewhere that $10 \mu \mathrm{mol} \mathrm{l}^{-1}$ of spermine stimulates PI4K and actin polymerization, and this stimulation is abrogated by $1 \mathrm{mmol} \mathrm{l}^{-1}$ spermine probably because of its binding to $\operatorname{PIP}_{2(4,5)}$ and preventing PLD activation. ${ }^{19}$ At the time of ejaculation, sperm are exposed to millimolar spermine. ${ }^{37}$ Spermine is taken up very fast by the sperm cells and released rapidly when incubated under capacitation conditions. ${ }^{38}$ Thus, we suggest that spermine appears to be a physiological regulator of PI4K activity.

Another phosphatidylinositol kinase is the phosphatidylinositol 3 kinase $\left(\mathrm{PI} 3 \mathrm{~K}\right.$ ) that can phosphorylate $\mathrm{PIP}_{2(4,5)}$ to produce phosphatidylinositol-3,4,5-triphosphate $\left(\mathrm{PIP}_{3(3,4,5)}\right) .^{39}$ Although $\mathrm{PIP}_{2(4,5)}$ and $\mathrm{PIP}_{3(3,4,5)}$ represent less than $1 \%$ of membrane phospholipids, they function in several crucial cellular processes. ${ }^{40} \mathrm{~A}$ role for PI3K has been suggested in sperm functions during sperm capacitation and the AR. ${ }^{19,41,42}$ We have recently shown that PI3K is significantly activated toward the end of the incubation under capacitation conditions and involved in the AR; however, it does not mediate F-actin formation in sperm capacitation. ${ }^{19}$ We also show PI3K-dependent $\operatorname{PIP}_{3(3,4,5}$ formation in sperm capacitation that is stimulated by activation of PKA. ${ }^{19}$ Thus, we suggest that under regular in vitro capacitation conditions PLD is a central regulator of F-actin formation during sperm capacitation, whereas PI3K is a major player in the AR. However, when PKA is overactivated by adding $8 \mathrm{Br}$-cyclic adenosine monophosphate (8Br-cAMP) $\left(1 \mathrm{mmol}^{-1}\right)$, we can see significant stimulation of PI3K activation, as well as PI3K-dependent F-actin formation.9,19 This observation led us to suggest that F-actin formation can be induced under various conditions: (i) when PKA activity is relatively low and PKC activity is high, enhancement of $\mathrm{PIP}_{2(4,5)}$ via activation of PI4K by spermine or PKC leads to PLD activation and actin polymerization. Under these conditions $\mathrm{PIP}_{3(3,4,5)}$ is not involved in actin polymerization; and (ii) when PKA activity is relatively high and PKC activity is downregulated, ${ }^{27}$ PKA enhances $\mathrm{PIP}_{2(4,5)}$ via activation of $\mathrm{PI} 3 \mathrm{~K}$, which activates PI4K and PI4P5K indirectly, leading to PLD activation and actin polymerization. ${ }^{19}$

\section{ROLE OF EGFR IN AR: LOCALIZATION OF EGFR AND EFFECT ON AR}

It was shown by others that EGFR is involved in boar sperm motility ${ }^{43}$ and were localized at higher extent to the acrosome region than to the post-acrosome and the flagellum. ${ }^{43}$ Moreover, EGF signaling was shown to be an important pathway identified in high fertility sperm in a recent comprehensive proteomic analysis. ${ }^{44}$ We previously show that bovine sperm express EGFR that is involved in the AR and in actin polymerization during sperm capacitation. ${ }^{9,17,18}$ We also show that EGFR was localized to the sperm head and midpiece, but not to the principal region of the tail..$^{9}$ The localization of EGFR in the head of sperm led us to investigate the role of EGFR in the AR. It was shown that EGF can induce the AR when added at the end of capacitation. ${ }^{9,10,17}$ It is well established that PI3K is a downstream effector of EGFR, and indeed, we have shown that inhibition of PI3K by $10 \mathrm{nmol} 1^{-1}$ wortmannin blocked the AR induced by EGF. Moreover, in a recent publication, we show that activation of $\mathrm{G}$ proteincoupled receptors (GPCRs), angiotensin II receptor type 1 or lysophosphatydic acid receptor causes transactivation of EGFR mediated by PKA and Src. ${ }^{9}$ Adding angiotensin II, lysophosphatydic acid or cAMP to capacitated sperm induced EGFR- and PI3K-dependent AR. ${ }^{9}$

To summarize the effect of EGF, we showed dual effects in which it enhanced F-actin formation during sperm capacitation, whereas in capacitated sperm, when F-actin level is already high, EGF causes F-actin breakdown (Figure 1). Our unpublished data revealed that the F-actinsevering protein gelsolin is inactive during sperm capacitation; therefore, we can see EGF-induced F-actin formation. However, before the AR, gelsolin can be activated by elevating intracellular $\mathrm{Ca}^{2+}$ concentration $\left(\left[\mathrm{Ca}^{2+}\right]_{i}\right)$ by EGFR activation causing F-actin breakdown.

\section{REGULATION OF SPERM EGFR}

We have shown elsewhere that GPCR activation can lead to PKA- and Src-dependent EGFR activation in bovine sperm. ${ }^{9}$ In other cell types, EGFR can be activated by GPCR through a process called transactivation. ${ }^{45-49}$ The majority of receptor tyrosine kinase transactivation by GPCRs in many cell types is mediated by metalloproteinase-dependent shedding, or by release of growth factor-like substances such as heparin-binding EGF, known as triple membrane-passing signals. ${ }^{50}$ In this mechanism, the GPCR activates a $\mathrm{Zn}^{2+}$-dependent metalloproteinase to cleave pro-heparin-binding EGF, releasing an EGF-like ligand, which binds to the EGFR and activates it. In some cases, the tyrosine kinase Src mediates the GPCR-EGFR transactivation process $^{51}$ by phosphorylating EGFR on Y845, known to be the Src tar- 


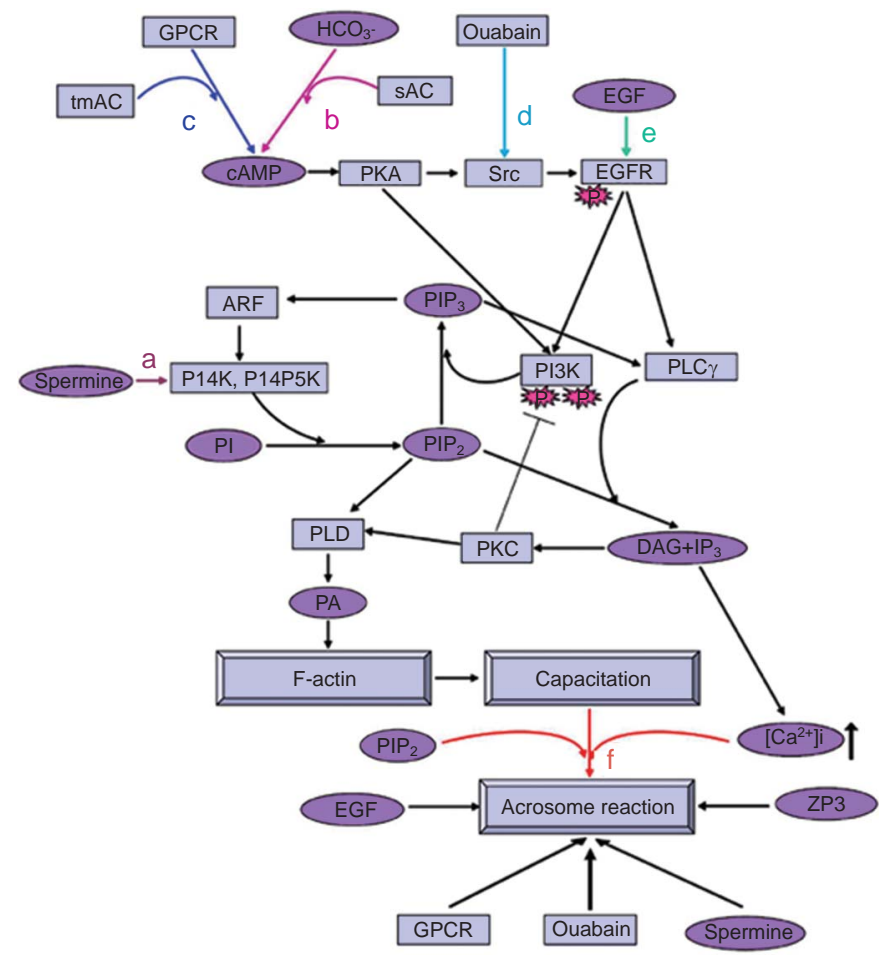

Figure 1 A model representing the mechanisms underlying EGFR activation during bovine sperm capacitation and AR. (a) Activation of PLD in sperm capacitation: at the beginning of the capacitation process, spermine can induce PI4K activation leading to PIP $_{2(4,5)}$ formation, ${ }^{19}$ a cofactor for PLD activation. The activation of PLD occurs by PKC $\alpha$, which is already activated at the beginning of the capacitation. ${ }^{82}$ PLD can also be activated by activating PKA. ${ }^{27}$ Activation of PLD leads to F-actin formation during sperm capacitation. ${ }^{27}$ (b-e) Partial activation of EGFR in sperm capacitation: the EGFR can be activated via EGF (e) or by the cAMP-dependent PKA/Src system by activating GPCRs, ${ }^{9}$ which activate membrane-bound adenylyl cyclase to form cAMP, by $\mathrm{HCO}_{3}^{-}, 7$ which activates the soluble adenylyl cyclase (b, c), or by ouabain (d), ${ }^{10}$ which activates the tyrosine kinase Src. The activated EGFR can lead to PLD activation and F-actin formation via activation of PI3K/ARF/PI4K to form $\mathrm{PIP}_{2}$ and via PLC/PKC, two pathways needed for PLD activation. The activation of PI3K is upregulated by PKA and downregulated by PKC. ${ }^{82}$ Full activation of the EGFR before the acrosome reaction: further activation of the EGFR at the end of the capacitation process, by GPCR activation, ouabain, CAMP or EGF, enhances $\left[\mathrm{Ca}^{2+}\right]_{i}^{9}$ and PI3K activity, leading to F-actin breakdown and the occurrence of the AR (f). The addition of exogenous $\mathrm{PIP}_{2}$ or spermine, which leads to intracellular $\mathrm{PIP}_{2}$ formation (f), can induce the acrosome reaction via stimulating $\mathrm{PIP}_{2}$ hydrolysis to form $\mathrm{IP}_{3}$, leading to mobilization and increase in $\left[\mathrm{Ca}^{2+}\right]_{i}$ and activation of actin-severing proteins to depolymerize $\mathrm{F}$-actin, resulting in the occurrence of the acrosome reaction (f). $\left[\mathrm{Ca}^{2+}\right]_{i}$, intracellular $\mathrm{Ca}^{2+}$ concentration; cAMP, cyclic adenosine monophosphate; DAG, diacylglycerol; EGF, epidermal growth factor; EGFR, epidermal growth factor receptor; GPCR, G protein-coupled receptor; $\mathrm{IP}_{3}$, inositol 1,4,5triphosphate; PA, phosphatidic acid; PI3K, phosphatidylinositol 3-kinase; PI4K, phosphatidylinositol 4-kinase; PI4P5K, phosphatidylinositol 4-phosphate 5-

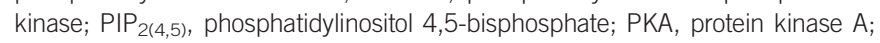
PKC, protein kinase C; PLC, phospholipase C; PLD, phospholopase D; SAC, soluble adenylyl cyclase; tmAC, transmembrane adenylyl cyclase; ZP, zona pellucida.

get. $^{52-54}$ This phosphorylation (Y845) in the kinase domain is implicated in stabilizing the activation loop and maintaining the active state of the receptor. ${ }^{55,56}$ EGFR-Y845 phosphorylation can lead to the activation of the EGFR by autophosphorylation that leads to the activation of various cascades. These cascades include the mitogenactivated protein kinase cascade ${ }^{57}$ and PI3K cascade ${ }^{58}$ that are activated by phosphorylation of EGFR-Y1068 and were shown to regulate the AR. ${ }^{42,59,60}$ As mentioned above, EGFR in sperm can be activated by agonists of two GPCRs, angiotensin II receptor type 1 and lysophosphatydic acid receptor, ${ }^{9}$ indicating that EGFR transactivation occurs in sperm. Moreover, we have shown that these agonists induce the AR that is mediated by EGFR activation. ${ }^{9}$

This EGFR transactivation is mediated by the tyrosine kinase Src that is known to be involved in sperm capacitation and the AR. 9,10,61,62 In human sperm, Src was found in the flagellum and head and was localized to membrane fraction. ${ }^{63}$ Src is also involved in protein tyrosine phosphorylation and motility during sperm capacitation. ${ }^{62,64}$ It was shown that Src forms a complex with PKA that can phosphorylate and activate Src. ${ }^{62,63}$ Recently, Src was localized to the post-acrosomal region of the head, neck and mid-piece of human sperm. ${ }^{63}$ Src was found to be activated during human sperm capacitation and appears to be involved in regulating sperm capacitation, calcium fluxes, tyrosine phosphorylation and the AR. ${ }^{9,10,65}$ In a recent study, it has been suggested that the Src downregulates protein phosphatase 2, resulting in the increase of protein tyrosine phosphorylation in sperm capacitation. ${ }^{66}$ In our work, we have shown that Src is involved in bovine sperm capacitation and AR through regulation of the EGFR activation. ${ }^{9}$ Moreover, we show that the AR induced by AngII or lysophosphatydic acid is mediated by the transactivation of the EGFR via a mechanism involving Src and PKA. ${ }^{9}$

The EGFR signal transactivation can also be induced by treating cells with ouabain, a specific inhibitor of $\mathrm{Na}^{+} / \mathrm{K}^{+}$-ATPase. ${ }^{67}$ The $\mathrm{Na}^{+}$/ $\mathrm{K}^{+}$-ATPase is a heteromeric, integral membrane $\mathrm{Na}^{+} / \mathrm{K}^{+}$exchange protein. The enzyme consists of two subunits: the $\alpha$-subunit contains the catalytic function and the cation, ouabain and ATP-binding sites, ${ }^{68}$ whereas the $\beta$-subunit is necessary for localization to the plasma membrane ${ }^{69-72}$ and stabilization of the $\mathrm{K}^{+}$-occluded intermediate form of the protein. ${ }^{73,74}$ The $\alpha 4$ isoform has been identified only in the testes of several species ${ }^{75-78}$ and in bovine sperm. ${ }^{79}$ This isoform shows high affinity to ouabain, $\mathrm{Na}^{+}$and $\mathrm{K}^{+}$, and its activity is inhibited by low concentrations of ouabain $\left(10 \mu \mathrm{mol} \mathrm{l}^{-1}\right),{ }^{78,80}$ which also inhibits sperm motility. In recent studies, it was shown that $100 \mu \mathrm{mol} 1^{-1}$ ouabain induces bovine sperm capacitation without any effect on sperm motility. ${ }^{79,81}$ In a recent publication, we have shown that nanomolar concentration of ouabain is present in bovine semen and in vaginal fluids of the cow. ${ }^{10}$ Under in vitro conditions, ouabain at $10 \mathrm{nmol}^{-1}$ does not affect the AR; however, this concentration of ouabain together with a very low concentration of EGF $\left(0.1 \mathrm{ng} \mathrm{ml}^{-1}\right)$, can induce the AR that was found to be mediated by Src, PKA and EGFR activation. ${ }^{10}$

We have shown before that activation of PKA by adding 8Br-cAMP causes high activation of EGFR. ${ }^{3}$ It is well accepted that PKA is activated in sperm capacitation; thus it is expected to see some activation of the EGFR during capacitation even without adding its ligand to the incubation medium. Indeed, we found that the EGFR is partially activated in sperm incubated under capacitation conditions without any added ligand. ${ }^{9}$ This partial activation is not enough to induce the AR at the end of the capacitation, which can be induced by further activating the EGFR by its ligand EGF or by AngII, lysophosphatydic acid or ouabain. ${ }^{9,10}$ However, as mentioned above, physiological concentrations of ouabain or EGF alone cannot induce the AR in capacitated sperm, unless they added together. ${ }^{4}$ This is a unique way of receptor regulation by which two components that exist in the female reproductive tract are needed to fully activate the EGFR.

\section{CONCLUSION}

In the capacitation process, the EGFR is partially activated by PKA, resulting in PLD activation and actin polymerization. $\mathrm{PKC} \alpha$, which is 
already activated at the beginning of the capacitation, also participates in PLD activation. Further activation of the EGFR at the end of the capacitation enhanced $\left[\mathrm{Ca}^{2+}\right]_{i}$, leading to F-actin breakdown and allows the AR to take place. Under physiological conditions, the EGFR can be directly activated by EGF and/or indirectly by activating PKA or by transactivation mediated by GPCR activation or by ouabain. Sperm PKA is activated mainly by bicarbonate, which activates the soluble adenylyl cyclase to produce cAMP, the activator of PKA. The GPCR activators angiotensin II or lysophosphatidic acid, as well as ouabain and EGF, are physiological components present in the female reproductive tract.

\section{COMPETING FINANCIAL INTERESTS}

The authors declare no competing financial interests.

1 Florman HM, Ducibella T. Fertilization in mammals. In: Neill JD, editor. Physiology of Reproduction. San Diego, , CA: Elsevier; 2006. pp55-112.

2 Gadella BM, Visconti A. Regulation of capacitation. In: de Jonge CJ, Barratt C, editors. The Sperm Cell. Cambridge: Cambridge University Press; 2006. pp134-69.

3 Yanagimachi R, Chang MC. Fertilization of hamster eggs in vitro. Nature 1963; 200: 281-2.

4 Yanagimachi R, Knobil E, Neil JD. Mammalian fertilization. In: The Physiology of Reproduction. New York: Raven Press; 1994. pp189-317.

5 Roldan ER, Shi QX. Sperm phospholipases and acrosomal exocytosis. Front Biosci 2007; 12: 89-104.

6 Florman HM, Jungnickel MK, Sutton KA. Regulating the acrosome reaction. Int J Dev Biol 2008; 52: 503-10.

7 Breitbart $\mathrm{H}$. Signaling pathways in sperm capacitation and acrosome reaction. Cell Mol Biol 2003; 49: 321-7.

8 Wassarman PM, Jovine L, Litscher ES. A profile of fertilization in mammals. Nat Cell Biol 2001; 3: E59-64.

9 Etkovitz N, Tirosh $Y$, Chazan R, Jaldety $Y$, Daniel $L$ et al. Bovine sperm acrosome reaction induced by $\mathrm{G}$ protein-coupled receptor agonists is mediated by epidermal growth factor receptor transactivation. Dev Biol 2009; 334: 447-57.

10 Daniel L, Etkovitz N, Weiss SR, Rubinstein S, Ickowicz D et al. Regulation of the sperm EGF teceptor by ouabain leads to initiation of the acrosome reaction. Dev Biol 2010 344: 650-7.

11 Arnoult C, Zeng Y, Florman H. ZP3-dependent activation of sperm cation channels regulates acrosomal secretion during mammalian fertilization. J Cell Biol 1996; 134 $637-45$.

12 Wassarman PM. Early events in mammalian fertilization. Annu Rev Cell Biol 1987; 3: 109-42.

13 Baldi E, Krausz C, Forti G. Nongenomic actions of progesterone on human spermatozoa. Trends Endocrinol Metab 1995; 6: 198-205.

14 Roldan ERS, Murase T, Shi QX. Exocytosis in spermatozoa in response to progesterone and zona pellucida. Science 1994; 266: 1578-81.

15 Joyce CL, Nuzzo NA, Wilson L, Zaneveld LJD. Evidence for the role of cyclooxygenase (prostaglandin synthetase) and prostaglandins in the sperm acrosome reaction and fertilization. J Androl 1987; 8: 74-82.

16 Rotem R, Zamir N, Keynan N, Barkan H, Breitbart $\mathrm{H}$ et al. Atrial natriuretic peptide induces acrosomal exocytosis of human sperm. Am J Physiol 1998; 274: E218-23.

17 Lax Y, Rubinstein S, Breitbart H. Epidermal growth factor induces acrosoma exocytosis in bovine sperm. FEBS Lett 1994; 339: 234-8.

18 Brener E, Rubinstein S, Cohen G, Shternall K, Rivlin J et al. Remodeling of the actin cytoskeleton during mammalian sperm capacitation and acrosome reaction. Biol Reprod 2003; 68: 837-45.

19 Etkovitz N, Rubinstein S, Daniel L, Breitbart H. Role of PI3-kinase and PI4-kinase in actin polymerization during bovine sperm capacitation. Biol Reprod 2007; 77: 26373.

20 Tilney LG, Hatano S, Ishikawa H, Mooseker MS. The polymerization of actin: its role in the generation of the acrosomal process of certain echinoderm sperm. $J$ Cell Biol 1973; 59: 109-26.

21 Tilney LG. The role of actin in nonmuscle cell motility. Soc Gen Physiol Ser 1975; 30 : 339-88.

22 Breitbart H, Spungin B. The biochemistry of the acrosome reaction. Mol Hum Reprod 1997; 3: 195-202.

23 Spungin B, Breitbart H. Calcium mobilization and influx during sperm exocytosis. J Cell Sci 1996; 109: 1947-55.

24 Spungin B, Margalit I, Breitbart H. Sperm exocytosis reconstructed in a cell-free system: evidence for the involvement of phospholipase $C$ and actin filaments in membrane fusion. J Cell Sci 1995; 108 (Pt 6): 2525-35.

25 Gur Y, Breitbart H. Mammalian sperm translate nuclear-encoded proteins by mitochondrial-type ribosomes. Genes Dev 2006; 20: 411-6.
26 Zhao C, Guo XJ, Shi ZH, Wang FQ, Huang XY et al. Role of translation by mitochondrialtype ribosomes during sperm capacitation: an analysis based on a proteomic approach. Proteomics 2009; 9: 1385-99.

27 Cohen G, Rubinstein S, Gur Y, Breitbart H. Crosstalk between protein kinase A and C regulates phospholipase $\mathrm{D}$ and $\mathrm{F}$-actin formation during sperm capacitation. Dev Biol 2004; 267: 230-41.

28 Brown HA, Gutowski S, Moomaw CR, Slaughter C, Sternweis PC. ADP-ribosylation factor, a small GTP-dependent regulatory protein, stimulates phospholipase activity. Cell 1993; 75: 1137-44.

29 Colley WC, Sung TC, Roll R, Jenco J, Hammond SM et al. Phospholipase D2, a distinct phospholipase $\mathrm{D}$ isoform with novel regulatory properties that provokes cytoskeletal reorganization. Curr Biol 1997; 7: 191-201.

30 Hammond SM, Altshuller YM, Sung TC, Rudge SA, Rose K et al. Human ADPribosylation factor-activated phosphatidylcholine-specific phospholipase $D$ defines a new and highly conserved gene family. J Biol Chem 1995; 270: 29640-3.

31 Hammond SM, Jenco JM, Nakashima S, Cadwallader K, Gu Q et al. Characterization of two alternately spliced forms of phospholipase D1. Activation of the purified enzymes by phosphatidylinositol 4,5-bisphosphate, ADP-ribosylation factor, and Rho family monomeric GTP-binding proteins and protein kinase C-alpha. J Biol Chem 1997; 272: 3860-8.

32 Berridge MJ. Inositol trisphosphate and diacylglycerol: two interacting second messengers. Annu Rev Biochem 1987; 56: 159-93.

33 Nishizuka $Y$. The role of protein kinase $C$ in cell surface signal transduction and tumour promotion. Nature 1984; 308: 693-8.

34 Breitbart H, Lax Y, Rotem R, Naor Z. Role of protein kinase $\mathrm{C}$ in the acrosome reaction of mammalian spermatozoa. Biochem J 1992; 281: 473-6.

35 Dragileva E, Rubinstein S, Breitbart $\mathrm{H}$. Intracellular $\mathrm{Ca}^{2+}-\mathrm{Mg}^{2+}$-ATPase regulates calcium influx and acrosomal exocytosis in bull and ram spermatozoa. Biol Reprod 1999; 61: 1226-34.

36 Walensky LD, Snyder SH. Inositol 1, 4,5-trisphosphate receptors selectively localized to the acrosomes of mammalian sperm. J Cell Biol 1995; 130: 857-69.

37 Bamberg E, Weiser M, Desser H. Polyamines in bovine epididymal spermatozoa. $J$ Reprod Fertil 1975; 45: 363-5.

38 Rubinstein S, Breitbart $\mathrm{H}$. Role of spermine in mammalian sperm capacitation and acrosome reaction. Biochem J 1991; 278: 25-8.

39 Auger KR, Serunian LA, Soltoff SP, Libby P, Cantley LC. PDGF-dependent tyrosine phosphorylation stimulates production of novel polyphosphoinositides in intact cells. Cell 1989; 57: 167-75.

40 Czech MP. PIP 2 and $\mathrm{PIP}_{3}$ : complex roles at the cell surface. Cel/2000; 100: 603-6.

41 Fisher D, Abrieu A, Simon MN, Keyse S, Verge V et al. MAP kinase inactivation is required only for G2-M phase transition in early embryogenesis cell cycles of the starfishes Marthasterias glacialis and Astropecten aranciacus. Dev Biol 1998; 202: $1-13$.

42 Jungnickel MK, Sutton KA, Wang Y, Florman HM. Phosphoinositide-dependent pathways in mouse sperm are regulated by egg ZP3 and drive the acrosome reaction. Dev Biol 2007; 304: 116-26.

43 Oliva-Hernandez J, Perez-Gutierrez JF. Localization of the epidermal growth factor (EGF) in the epididymis and accessory genital glands of the boar and functional effects on spermatozoa. Theriogenology 2008; 70: 1159-69.

44 Peddinti D, Nanduri B, Kaya A, Feugang JM, Burgess SC et al. Comprehensive proteomic analysis of bovine spermatozoa of varying fertility rates and identification of biomarkers associated with fertility. BMC Syst Biol 2008; 2: 19.

45 Jorissen RN, Walker F, Pouliot N, Garrett TP, Ward CW et al. Epidermal growth factor receptor: mechanisms of activation and signalling. Exp Cell Res 2003; 284 31-53.

46 Jung J, Kim M, Choi S, Kim MJ, Suh JK et al. Molecular mechanism of cofilin dephosphorylation by ouabain. Cell Signal 2006; 18: 2033-40.

47 Prenzel N, Zwick E, Daub H, Leserer M, Abraham R et al. EGF receptor transactivation by G-protein-coupled receptors requires metalloproteinase cleavage of proHB-EGF. Nature 1999; 402: 884-8.

48 Shah $\mathrm{BH}$, Catt KJ. A central role of EGF receptor transactivation in angiotensin II induced cardiac hypertrophy. Trends Pharmacol Sci 2003; 24: 239-44.

49 Wetzker R, Bohmer FD. Transactivation joins multiple tracks to the ERK/MAPK cascade. Nat Rev Mol Cell Biol 2003; 4: 651-7.

50 Prenzel N, Zwick E, Leserer M, Ullrich A. Tyrosine kinase signalling in breast cancer Epidermal growth factor receptor: convergence point for signal integration and diversification. Breast Cancer Res 2000; 2: 184-90.

51 Nair VD, Sealfon SC. Agonist-specific transactivation of phosphoinositide 3-kinase signaling pathway mediated by the dopamine D2 receptor. J Biol Chem 2003; 278: 47053-61.

52 Tice DA, Biscardi JS, Nickles AL, Parsons SJ. Mechanism of biological synergy between cellular Src and epidermal growth factor receptor. Proc Natl Acad Sci USA 1999; 96: 1415-20

53 Prenzel N, Fischer OM, Streit S, Hart S, Ullrich A. The epidermal growth factor receptor family as a central element for cellular signal transduction and diversification. Endocr Relat Cancer 2001; 8: 11-31.

54 Liu J, Liao Z, Camden J, Griffin KD, Garrad RC et al. Src homology 3 binding sites in the P2Y2 nucleotide receptor interact with $\mathrm{Src}$ and regulate activities of $\mathrm{Src}$, proline-rich tyrosine kinase 2, and growth factor receptors. J Biol Chem 2004; 279: 8212-8.

55 Cooper JA, Howell B. The when and how of Src regulation. Cell 1993; 73: 1051-4.

56 Hubbard SR, Wei L, Ellis L, Hendrickson WA. Crystal structure of the tyrosine kinase domain of the human insulin receptor. Nature 1994; 372: 746-54. 
neg

EGFR and actin in sperm

$\mathrm{H}$ Breitbart and N Etkovitz

110

57 Rojas M, Yo S, Lin YZ. Controlling epidermal growth factor (EGF)-stimulated Res activation in intact cells by a cell-permeable peptide mimicking phosphorylated EGF receptor. J Biol Chem 1996; 271: 27456-61.

58 Gao Z, Li L, van Winkle DM. Met5-enkephalin-induced cardioprotection occurs via transactivation of EGFR and activation of PI3K. Am J Physiol Heart Cire Physio 2005; 288: H1955-64.

59 Almog T, Lazar S, Reiss N, Etkovitz N, Milch E et al. Identification of extracellular signal-regulated kinase $1 / 2$ and $\mathrm{p} 38 \mathrm{MAPK}$ as regulators of human sperm motility and acrosome reaction and as predictors of poor spermatozoa quality. J Biol Chem 2008; 283: 14479-89.

60 Breitbart H, Rubinstein S, Etkovitz N. Sperm capacitation is regulated by the crosstalk between protein kinase A and C. Mol Cell Endocrinol 2006; 252: 247-9.

61 Reinton N, Orstavik S, Hagen TB, Jansen T, Taken $\mathrm{K}$ et al. A novel isoform of human cyclic $3^{\prime}, 5^{\prime}$-adenosine monophosphate-dependent protein kinase, $\mathrm{c}$ alphas, localizes to sperm midpiece. Biol Reprod 2000; 63: 607-11.

62 Baker MA, Hetherington L, Aitken RJ. Identification of SRC as a key PKA-stimulated tyrosine kinase involved in the capacitation-associated hyperactivation of murine spermatozoa. J Cell Sci 2006; 119: 3182-92.

63 Lawson C, Goupil S, Leclerc P. Increased activity of the human sperm tyrosine kinase SRC by the CAMP-dependent pathway in the presence of calcium. Biol Reprod 2008; 79: 657-66.

64 Mitchell LA, Nixon B, Baker MA, Aitken RJ. Investigation of the role of SRC in capacitation-associated tyrosine phosphorylation of human spermatozoa. Mol Hum Reprod 2008; 14: 235-43.

65 Varano G, Lombardi A, Cantini G, Fort G, Bald E et al. Sc activation triggers capacitation and acrosome reaction but not motility in human spermatozoa. Hum Reprod 2008; 23: 2652-62.

66 Krapf D, Arcelay E, Wertheimer EV, Sanjay A, Pilder SH et al. Inhibition of Ser/Thr phosphatase induces capacitation-associated signaling in the presence of Sic kinase inhibitors. J Biol Chem 285: 7977-85.

67 Haas M, Askari A, Xii Z. Involvement of Sic and epidermal growth factor receptor in the signal-transducing function of $\mathrm{Na}^{+} / \mathrm{K}^{+}$-ATPase. J Biol Chem 2000; 275: $27832-7$.

68 Lingrel JB, Kuntzweiler T. Na ${ }^{+}, \mathrm{K}^{+}$-ATPase. J Biol Chem 1994; 269: 19659-62.

69 Beguin P, Hailer U, Beggah A, Horisberger JD, Cering K. Membrane integration of $\mathrm{Na}, \mathrm{K}-\mathrm{ATP}$ sse alpha-subunits and beta-subunit assembly. J Biol Chem 1998; 273: 24921-31.
70 Goering K. The functional role of the beta-subunit in the maturation and intracellular transport of Na,K-ATPase. FEBS Lett 1991; 285: 189-93.

71 Hasler U, Wang X, Crambert G, Beguin P, Jaisser F et al. Role of beta-subunit domains in the assembly, stable expression, intracellular routing, and functional properties of Na, K-ATPase. J Biol Chem 1998; 273: 30826-35.

72 McDonough AA, Geeing K, Farley RA. The sodium pump needs its beta subunit. FASEB J 1990; 4: 1598-605.

73 Eakle KA, Kabalin MA, Wang SG, Farley RA. The influence of beta subunit structure on the stability of $\mathrm{Na}^{+} / \mathrm{K}^{+}$-ATPase complexes and interaction with $\mathrm{K}^{+}$. J Biol Chem 1994; 269: 6550-7.

74 Lutsenko S, Kaplan JH. An essential role for the extracellular domain of the $\mathrm{Na}, \mathrm{K}$ ATPase beta-subunit in cation occlusion. Biochemistry (Moss) 1993; 32: 6737-43.

75 James PF, Grip IL, Krupp G, Woo AL, Askew GR et al. Identification of a specific role for the Na,K-ATPase alpha 2 isoform as a regulator of calcium in the heart. Mol Cell 1999; 3: 555-63.

76 Shamraj OI, Lingrel JB. A putative fourth $\mathrm{Na}^{+}, \mathrm{K}^{+}$-ATPase alpha-subunit gene is expressed in testis. Proc Natl Accad Sci USA 1994; 91: 12952-6.

77 Underhill DA, Canfield VA, Dahl JP, Gros P, Levenson R. The Na, K-ATPase alpha gene (At plat) encodes a ouabain-resistant alpha subunit and is tightly linked to the alpha gene (Atp1a2) on mouse chromosome 1. Biochemistry (Moss) 1999; 38: 14746-51.

78 Woo AL, James PF, Lingrel JB. Sperm motility is dependent on a unique isoform of the Na, K-ATPase. J Biol Chem 2000; 275: 20693-9.

79 Newton LD, Kastelic JP, Wong B, van der Hoorn F, Thundathil J. Elevated testicular temperature modulates expression patterns of sperm proteins in Holstein bulls. Mol Reprod Devi 2009; 76: 109-18.

80 Blanco G, Melton RJ, Sanchez G, Mercer RW. Functional characterization of a testesspecific alpha-subunit isoform of the sodium/potassium adenosinetriphosphatase. Biochemistry (MosS) 1999; 38: 13661-9.

81 Thundathil JC, Anzar M, Buhr MM. $\mathrm{Na}^{+} / \mathrm{K}^{+}$-ATPase as a signaling molecule during bovine sperm capacitation. Biol Reprod 2006; 75: 308-17.

82 Rotman T, Etkovitz N, Spiegel A, Rubinstein S, Breitbart H. Protein kinase A and protein kinase C(alpha)/PPP1CC2 play opposing roles in the regulation of phosphatidylinositol 3-kinase activation in bovine sperm. Reproduction 2010; 140: 43-56.

Asian Journal of Andrology 